This item was submitted to Loughborough's Research Repository by the author.

Items in Figshare are protected by copyright, with all rights reserved, unless otherwise indicated.

\title{
A software tool for evaluating the effects of culture on military operations
}

PLEASE CITE THE PUBLISHED VERSION

PUBLISHER

(c) AAAI

VERSION

AM (Accepted Manuscript)

LICENCE

CC BY-NC-ND 4.0

REPOSITORY RECORD

Hodgson, Allan, and Carys E. Siemieniuch. 2019. "A Software Tool for Evaluating the Effects of Culture on Military Operations”. figshare. https://hdl.handle.net/2134/4853. 
This item was submitted to Loughborough's Institutional Repository (https://dspace.lboro.ac.uk/) by the author and is made available under the following Creative Commons Licence conditions.

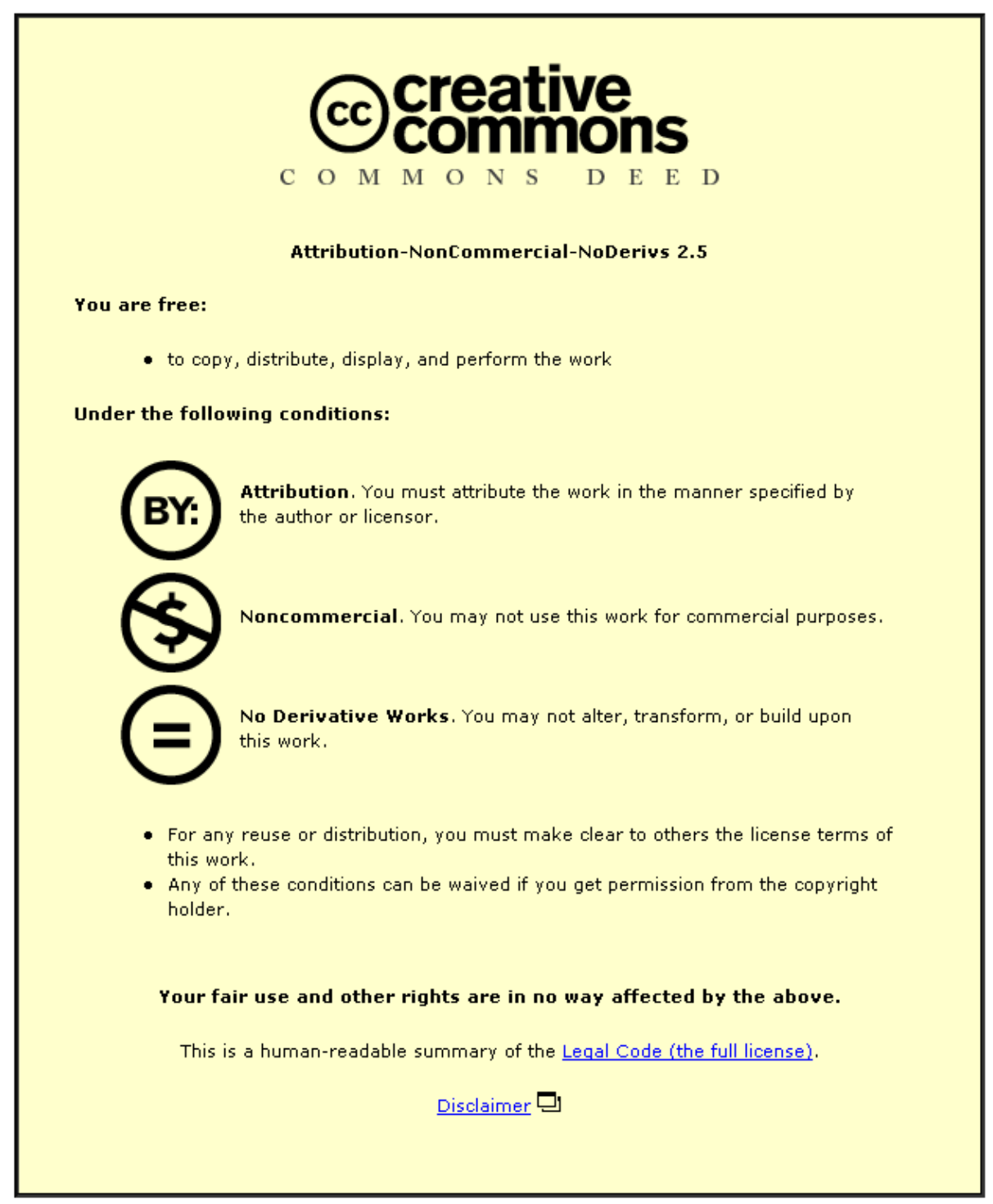

For the full text of this licence, please go to: http://creativecommons.org/licenses/by-nc-nd/2.5/ 


\title{
A software tool for evaluating the effects of culture on military operations
}

\author{
A Hodgson and Dr C E Siemieniuch
}

\author{
Loughborough University \\ SEAS DTC, Dept of Electrical and Electronic Engineering, UK \\ a.hodgson@lboro.ac.uk \\ c.e.siemieniuch@lboro.ac.uk
}

\begin{abstract}
This paper presents the military rationale for developing an improved understanding of the effects of culture on the performance of military organizations and their partners. In particular the change from conventional high intensity warfare to asymmetric warfare increases the interactions between different cultures within multi-national military forces and in the local populations. A brief description of culture and cultural attributes is presented. A culture-based evaluation tool (the Soft Factors Modeling Tool), which has been developed by the authors, is described.
\end{abstract}

\section{Introduction}

Research and development activities in the civilian sector have produced a range of systems, products and areas of knowledge that in many cases could benefit military systems. In order to exploit this, the UK Ministry of Defence has funded the creation of a number of Defence Technology Centres in the UK, in order to capture the best of both military and civilian developments and to implement them to improve defense technology and defense systems. The research work reported in this paper is funded by the UK's Systems Engineering for Autonomous Systems Defence Technology Centre (SEAS DTC).

There is an increasing recognition of the potentially deleterious effects of incompatible individual and organizational cultures on complex systems and organizations. In the case of the military, these effects are exacerbated by the increasing involvement of multinational forces and nongovernmental organizations as the World moves into an era of 'asymmetric warfare'. Two quotes from the National Academies Report "Human Behavior in Military Contexts' (Flascovich \& Hartel 2008) capture the problem:

The ability to navigate and adapt to different cultures is known as intercultural competence or cultural intelligence ... thus a key issue for the military is to select, train and deploy individuals who possess these qualities and are able to function in multiple cultures.

Note that the key word for this research is 'deploy'.

...modern conflicts such as the one in Iraq often involve more protracted engagement with local inhabitants and are rife with opportunities for intercultural misunderstandings.

\section{Military rationale}

Major changes are occurring to the post Cold War environments in which the British, American and other Western armed forces are operating. These changes and the requirements they place on Western armed forces are described briefly in this section.

\section{The increasing frequency of asymmetric warfare}

In military terms, the USA is now virtually unchallengeable. In terms of nuclear and conventional high intensity warfare capability, it has acquired such dominance that it is unlikely to be challenged directly in the foreseeable future. However, this hegemony, by limiting the military options of would-be foes, has forced them to select alternative, indirect, asymmetric approaches. In particular, this has come to mean some form of 'complex irregular warfare' (International Institute for Strategic Studies, 2005).

In 1999, Chinese military planners published a book entitled 'Unrestricted Warfare' (Qiao \& Wang, 1999). This book described a range of tactics that developing countries could adopt during a war in order to compensate for their military inferiority compared to the USA. The book also predicted a variety of asymmetric attacks against the USA, listing examples that included the bombing of the World Trade Center, attacks by bin Laden and hacking into (civilian) networks. The book was published in the West in 2002 (Qiao \& Wang 2002). During the late 1990s and the first two years of the new millennium, the USA had been embarking on a transformation of its military capability based on ever-smarter technology, involving space assets, precision weapons, reductions in conventional forces, etc. The 9/11 attacks (of 2001) against the U.S. provided a timely warning that these nascent transformations represented a costly mistake, and enabled the U.S. military to adjust to at least some extent to the new threats of asymmetric/complex irregular warfare.

Following the 9/11 attacks, Western strategists have realized that the West will not only face asymmetric warfare threats from terrorists based in 'failed states', but 
also from developing countries such as China, which have already tested and evaluated asymmetric warfare capabilities (Schneider 2007, Norton-Taylor 2007). The West cannot circumvent these asymmetric threats by using proxy forces abroad, as Western countries are easy to enter due to their ethnic mix, liberal laws, transport links, etc., their financial systems, services and civilians are easily attacked, and their populations are for the most part unused to internal threats. It is therefore generally accepted that it will be necessary to project force wherever the perceived enemy is detected.

Hoffman (2006) presents a valuable analysis of the U.S. military, its limited reactions to-date to the increasing asymmetric threats, and the requirements for further change to enable it to meet these threats. In a later article (Hoffman 2007), he describes the future scenario of 'hybrid wars', in which politically and ideologicallymotivated opponents use modern information networks and weapons to attack the West's weak points.

Krause (2007) presents an Australian perspective on the changing form of warfare. He states that asymmetric warfare, in its various forms, is likely to be the dominant form of combat in the future. Adversaries will exploit the West's weaknesses, including the media (which magnifies Western casualties and operational errors) and the squeamishness of Western public opinion which hamstrings the actions of its military forces, but not the actions of asymmetric opposition forces.

\section{A need for changes in Western military forces}

Hoffman (2006) considers that the USA's military reform programs are still too influenced by the former assumptions of high intensity warfare. In the future, forces are likely to arrive in an austere environment and have to fight immediately, rather than rely on well-equipped fixed bases.

One of Krause's key conclusions is that the primary training programs for Western armies must be for asymmetric warfare, rather than for high intensity conventional warfare as at present; asymmetric warfare cannot be left to the various nations' Special Forces (Krause 2007). Multinational forces will have to acquire a good understanding of each others' cultures and modes of operation, as well as the cultures and preferences of the populations and a range of non-governmental organizations with which they have to operate and collaborate.

The Western soldier will in future operate increasingly in vulnerable situations, where he or she is always effectively on the front line, facing surprise attack, hostagetaking and arbitrary changes in local alliances amongst armed groups who use the civilian population to shield themselves. It is important to reduce the risks that this soldier faces, wherever possible; this risk reduction will come about via more appropriate training, improved weaponry and physical protection and improved information (via networks, surveillance systems, etc.).

Based on more than fifty years experience of antiterrorist activities at home and abroad, the UK Ministry of Defence is well aware of many of the issues associated with low-level asymmetric warfare, including the effects of mounting military casualty levels and attacks against civilians on home soil. It is unlikely that the UK will be able to recruit significantly more soldiers in the future and, in order to meet the increasing commitment to asymmetric warfare, it must improve the relevant capabilities of existing soldiers, provide appropriate technologies to protect them and minimize the need for risk taking.

The UK Ministry of Defence believes that much greater reliance must, in the future, be placed on unmanned systems for surveillance, communications, targeting and as weapon platforms.

\section{The project}

The Systems Engineering for Autonomous Systems Defence Technology Centre (SEAS DTC) is the fourth DTC to be established by the UK's Ministry of Defence. The DTC carries out research into autonomous systems and sub-systems, with the intention of injecting the resultant technologies into unmanned military systems, in particular, autonomous and semi-autonomous vehicles that can reduce the hazards and costs associated with human operators.

Although much greater reliance will be placed in the future on unmanned systems, it is expected that humans will retain the ultimate responsibility for control and decision making with regard to the operational deployment of such systems. However, the position of the control interface and the allocation of decision-making autonomy to such a system will vary depending on the embedded intelligence within the overall system, task requirements, context, etc.

It is recognized within the SEAS DTC that personal culture and organizational culture have a significant effect on the effectiveness of military units. Therefore, the DTC is funding research projects covering cultural issues - the work of one such project, Impact of Different Cultural Attribute Sets on Semi/Autonomous System Decision Structures and Interfaces, is the main focus of this paper.

One of the first tasks of the above research project was to carry out a major review of the literature related to culture and its effects, in particular with regard to the military (Siemieniuch \& Meese 2006). The outputs of this survey covered twenty-four topics, including:

- What is culture?

- National culture

- Professional culture

- Organizational culture

- Military culture

- Cross-cultural operations

- Transforming culture

- Cultural dimensions

These outputs provided an essential guide to the subsequent activities of the research project. 


\section{Research aims of the project}

The research described in this paper is intended to develop innovative ways of evaluating the effects of culture on the performance of semi-autonomous/autonomous systems, and the performance of various combinations of military and non-governmental organisations.

A tool that can evaluate individual, group and organisation cultures and compare these against environmental/mission and behavioural requirements will not only aid the evaluation of the appropriateness of existing combinations of humans and technological systems, but will also assist in the selection of combinations for new scenarios and missions.

\section{Cultural scenarios of interest}

There are five key areas where culture has a particular role to play; these are described below:

1. Increasingly powerful soldiers: The advent of advanced autonomous and semi-autonomous systems is putting greater power than ever before in the hands of individual soldiers, and it is important that they make appropriate decisions with regard to the use of such power; individual, group and organizational culture play a significant part in such soldiers' effectiveness.

2. Effects-based operations and force packaging: UK and US forces are moving towards 'effects-based operations', where performance measures are based on the achievement of objectives, not the provision of fire power. Dorman (2008) describes the experience of the UK in its ongoing transformation to effects-based operations. 'Force packaging' (modular, self-contained sets of units borrowed from the various commands for a given mission) is an important contributor to this approach. Force packages can be assembled at short notice to form a mix of force appropriate for the specific demands of an unforeseen crisis demanding the use of armed forces. In the networkenabled capability (NEC) battle space, interoperability across these units is critical to effective collaboration and decision-making among different service cultures, which have been brought together at very short notice to deal with a crisis situation.

3. Multinational and non-governmental organisations: Multinational forces are increasingly being deployed, typically working alongside non-governmental organisations (NGOs) and operating in conflict, peace-making and peace-keeping roles. However, the various organisations come from and operate within different cultural contexts and, as systems, will exhibit a range of cultural attributes which impact on decision making and decision execution processes and thereby increase the likelihood of disagreements and misunderstandings in communicating and implementing 'commander's intent'.

4. Local populations: Military forces are spending ever longer in foreign countries. To achieve success, they need to interact in culturally sensitive ways with the local popu- lations of the host countries in order to move on from intervention to engagement.

5. The development of semi/autonomous systems: The development, implementation and use of technology, such as semi/autonomous systems (S/AS), do not occur in a vacuum. Designers make their own culturally-biased assumptions about user requirements and expectations. Organisational and military research shows that technology tends to be adopted by users for their own purposes, and exactly how it is used is heavily influenced by the extant organisational culture.

\section{Cultural perspectives}

Culture is a major and, to-date, underestimated factor in the performance of any complex system. Cultural effects can be examined at the level of the individual, the team, the organization; however, culture also affects the design of systems (whether or not they contain humans). Hofstede's 1984 definition of culture is regarded by the research team as a useful 'working basis':

Culture is "the collective programming of the mind which distinguishes the members of one human group from another ... includes systems of values; and values are among the building blocks of culture."

Hofstede (1991) states that there are three broad perspectives on culture, as depicted in Figure 1.

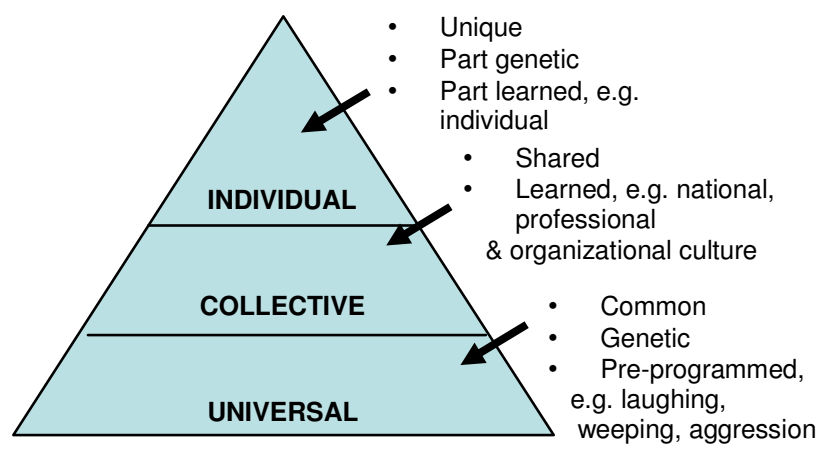

Figure 1: Hofstede's perspectives on culture

The perspectives that are amenable to change are at the individual and the collective culture levels. Hofstede uses the term 'cultural values' where value is seen as 'a broad tendency to prefer certain states of affairs over others'. In this project the term 'cultural attributes' has been used to describe a set of high level culture-related features, the values of which can be used to describe individuals and systems (including technical systems).

The Loughborough University research team has decided to focus on three widely accepted classes of culture, each of which could individually and collectively influence the set of cultural attributes exhibited by an individual or a collective such at a team, organization or system. 


\section{National culture}

National culture is usually a product of heritage (religion, history, language, climate, population density, availability of resources, politics, etc.). The following can vary according to national culture and can therefore shape expectations and performance:

- Leadership styles (hierarchical vs. consultative)

- Superior - inferior relationships (accept vs. question decisions)

- Communication styles (direct and specific vs. indirect and non-specific)

- Reading emotional reaction (showing reaction, emotion or aggression vs. hiding reaction)

- Following vs. breaking rules

\section{Professional culture}

Professional culture is usually manifested in its members by a sense of community and by the bonds of a common identity (Helmreich \& Merritt, 1998). Attributes of professional culture can include:

- Members have specific expertise and a shared professional jargon

- Norms for behavior and common, binding ethical values

- Selectivity and competition for entry

- Prestige and status with badges or defining uniform

- Extensive training requirements

- Professional and gender stereotyping

- Status differentials

- Self-regulation

- Institutional and individual resistance to imposed change

- Reluctance to admit error and denial of 'vulnerability'

- Reduced awareness of personal limitations

\section{Organizational culture}

There are two layers of organizational culture:

- Formal, surface, visible structures, including members' uniforms, symbols, routines, documents, etc.

- Informal, inner, invisible layer, including values, beliefs, subconscious assumptions.

Organizational culture is more amenable to influence than professional or national culture and it is organizational culture that effectively channels the effects of the other two cultures into standard working practices. Organizational culture is also unique, and what works in one organization may not work in another, and may not work at a different branch of the same organization. Factors thought to influence or engender organizational culture include:

- Reduced awareness of personal limitations

- Strong corporate identity such as the nature of the product and market in which the organization operates
- Effective leadership - moral association or belief in the organization's mission and products

- High morale and trust - confidence e.g. in quality and safety practices, management communication and feedback

- Cohesive team working and cooperation

- Job security

- Development \& training

- Degree of empowerment

\section{Cultural attributes}

It is the view of the researchers that, in contrast to most work on culture, some of the cultural attributes described in this section can be exhibited by technical elements such as intelligent software agents, as well as by humans. Since systems comprise both technical and non-technical elements, the technical components of semi/autonomous systems will also need to demonstrate appropriate decisionmaking behaviors and an ability to perform in particular environments.

Technical sub-systems or agents are designed by humans, and it is inevitable that positions on the cultural attribute pairings will, in many cases be inherent in the design of these technical subsystems, in particular where there is intelligence in the sub-system.

\section{Overview of the chosen cultural attributes}

As stated earlier, the research team carried out an in-depth state-of-the-art review. Based on the outputs of the review, an initial set of cultural attribute pairing was selected and incorporated into the first prototype of what is currently called the Soft Factors Modeling Tool.

Based on expert evaluation and further research these attributes have been modified and system cultural profiles are now assessed via ten culture attribute pairings, of which five can only be exhibited by the human agents in a system; the other five attributes can be exhibited by both human (i.e. non-technical) and technical (i.e. softwarebased) agents within a system, as indicated in Figure 2.

The project researchers believe that there is an identifiable relationship between the configuration of cultural attributes exhibited by a system (comprising both human and technical agents and components) and the performance of that system in a particular environment.

Cultural attributes can relate to the perceptions of a single agent (e.g. an individual or missile launcher), a group of sub-systems (a troop or a communications infrastructure) or an overall system (the army or the set of assets carrying out a mission). Each attribute pairing defines a range, with a description of the likely beliefs, perceptions, etc., manifested at each end. Individuals, groups or systems will select a position towards one end or the other, but rarely occupy the absolute extremes in all contexts. It should be remembered that the attribute ranges, of themselves, do not imply right or wrong, merely that the attri- 
bute value is more or less appropriate given a required level of performance in a particular environment.

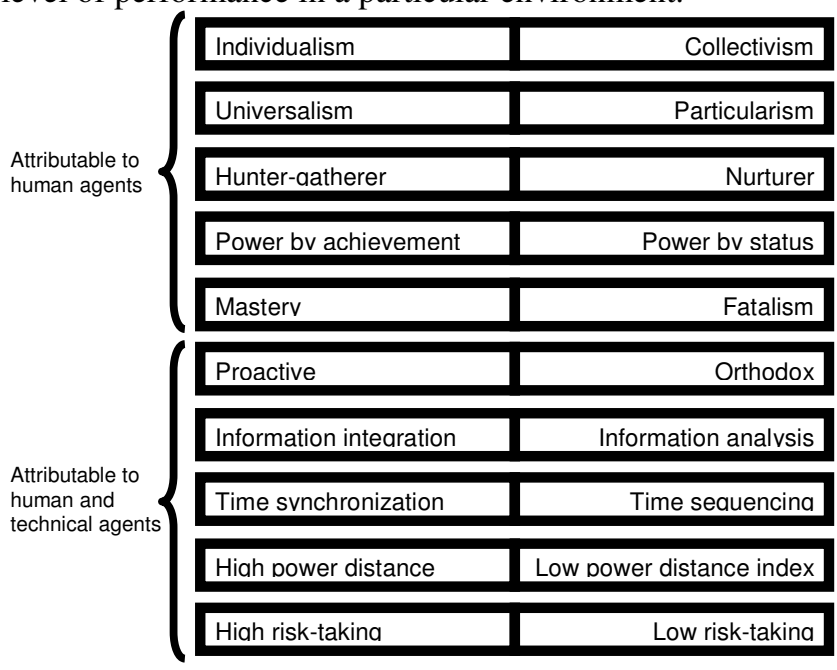

Figure 2: Cultural attribute pairings

There is insufficient space to present detailed descriptions of all ten attribute pairings, therefore only three examples are provided below. Further details of most of these are provided in Johnson et al. (2007).

Individualism vs. collectivism: This refers to the balance struck between individuals and groups. In individualistic societies, ties between individuals (other than immediate family members) are loose; each person takes responsibility for his or her actions; individualists tend to speak directly and factually, and are willing to argue and to question others' views. Generally, individualists tend to exhibit a higher level of trust than collectivists. In collectivistic societies, individuals are integrated into closely knit groups, often in the form of extended families; in return for unquestioning loyalty, they gain the protection of their group. People from outside the group tend to be treated with suspicion. Collectivists try to avoid direct, confrontational approaches and find criticizing others difficult. Hierarchies tend to be rigid, and losing face is to be avoided at all costs.

Proactive vs. orthodox: This refers to the application of doctrine, taught strategy and standard procedures vs. the need to adapt or create procedures to fit exceptional circumstances. Proactive implies that local characteristics can justify exceptions, where new local versions of rules and procedures should be generated and applied rather than force-fitting existing ones, e.g. for special force operations or some diplomatic/peace-keeping operations. Orthodox implies that broad or general formalized rules of operation are available and mandatory; the requirement is to find the best fit. This approach is useful for larger operations where cohesion over tactics and orders is critical.

High risk-taking vs. low risk-taking: This refers to the level of willingness and ability to take risks to achieve operational goals. High risk-taking implies an acceptance or relish of the unpredictable in military operations - being able to manage and react to chaotic events, a willingness or ability to bend or break rules and accept the consequences, an ability to think and evaluate the unthinkable. Low risktaking implies a respect for and acceptance of the need and importance of doctrine, strategy and standard operating procedures (SOPs), a more cautious approach to new situations, absence of the 'hero' factor, desire for a long-term stable career, preference for predictable, coherent approaches, great concern for possible consequences.

Note that military planners tend to differentiate between risk-taking (where there are fall-back options) and taking chances (where the cost of failure may be extremely high for the organization).

\section{The Soft Factors Modeling Tool}

The Loughborough researchers have developed a webbased prototype tool - the Soft Factors Modeling Tool (SFMT); this incorporates the cultural attribute pairings described in the previous section.

The latest version of the SFMT, although not yet complete, enables individuals and representatives of subsystems (e.g. teams, squads, platoons, command \& control (C2)) to input estimates of their positions with regard to each of the cultural attribute pairings. These positions are converted into numeric values and, when all data has been entered, feedback is presented to the user(s) in graphical format to highlight any conflicts between cultural attributes at the various system levels. So, for example the tool could be used by an individual or group who would review each of the assets under consideration for a particular mission and, by entering values against each of the cultural attributes will be able to generate a cultural profile of those assets. The tool will crunch the numbers and then highlight:

- Any similarities or conflicts in cultural attribute values that exist between the various assets

- Areas where particular assets may show a cultural attribute value that will facilitate or inhibit a desired behavior or ability to operate in a selected environment

The target end-users of the final version of the tool are mission planners who are required to put together a system (comprising human and technical components) to carry out an operational requirement in a particular environment. For example the tool can help answer the question 'Is a particular configuration of military assets tasked with carrying out a mission capable of demonstrating appropriate decision-making, information processing, communication, adaptive skills \& behavior in an environment where the command style is control free, authority is delegated, operational tempo is unpredictable and the battle space is ill-defined?

Figure 3 illustrates a screen dump from an earlier version of the SFMT as the user is about to enter data about the sixth of ten attribute pairings. On completion of data entry for all ten attribute value pairings, the data is then processed by an analysis engine, and the results displayed using a simple traffic light system, as described later in this paper. 


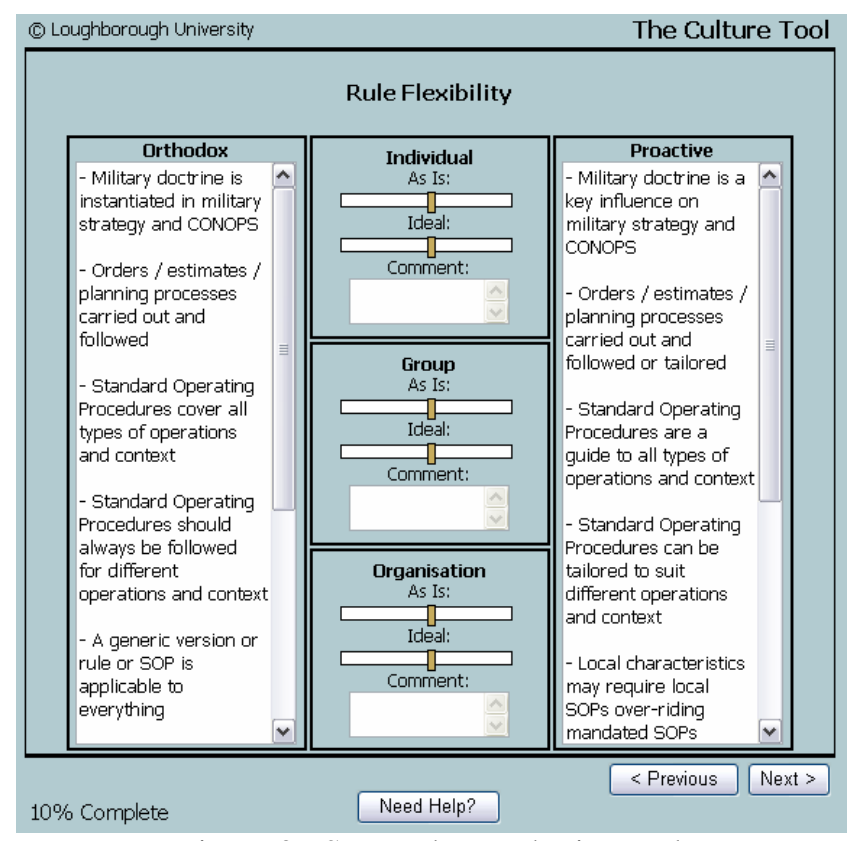

Figure 3: SFMT data gathering tool

Note that the data gathering tool and analysis engine have not yet been updated to the latest SFMT version. An earlier (draft) version of the tool has been available at http://www-staff.lboro.ac.uk/ ttgaln/Culture_web for some months. The modifications to produce the current version of the SFMT are based on initial feedback from a range of users and an analysis of the data collected.

\section{Impact of cultural attributes on behavior}

As already stated, a basic hypothesis of the research is that particular combinations of cultural attributes facilitate or inhibit certain types of decision-making behavior. For example, if a training assessor must have a communication behavior that includes stating factually his/her assessment of trainees' performances, then an agent occupying a position towards the collectivism end of the individualism vs. collectivism spectrum would not be an ideal candidate.

Table 1 illustrates a section of a spreadsheet that lists on the left a range of skill classes and, within these, behaviors. Cultural attribute pairs are listed across the spreadsheet and scored, although only one of these pairings, individualism vs. collectivism, is shown due to space limitations. The third and fifth columns of Table 1 indicate the capabilities of collectivism and individualism to achieve the various behaviors. Differing combinations of behaviors would be required for effective decision-making in various combat, peacemaking and peacekeeping situations.

The analysis engine evaluates the values input for the cultural attribute pairs against each of the classes of behavior of Table 1. A simple traffic light display system has been utilized for the software outputs - green implies that a position in this part of the pairing will facilitate the desired behavior, amber implies that the effect on the desired behavior is not clear or is neutral and red implies that a position in this part of the pairing will inhibit the ability of an agent or system to exhibit the desired behavior.

\begin{tabular}{|c|c|c|c|c|}
\hline Skill class & Desired behaviour & 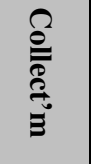 & 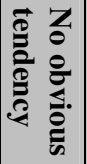 & $\begin{array}{l}\bar{\Xi} \\
\vdots \\
\bar{Z}\end{array}$ \\
\hline \multirow{6}{*}{$\begin{array}{l}\text { Communi- } \\
\text { cation \& } \\
\text { interaction } \\
\text { skills }\end{array}$} & Say what you mean/mean what you say & NEG & & POS \\
\hline & Convey meaning indirectly/diplomatically & POS & & NEG \\
\hline & Able to dispel conflict & & & \\
\hline & Able to trust and be trusted & NEG & & POS \\
\hline & Willing to collaborate/co-operate & & & \\
\hline & Transparency/openness & NEG & & POS \\
\hline \multirow{9}{*}{$\begin{array}{l}\text { Information } \\
\text { processing }\end{array}$} & Process information rapidly & & & \\
\hline & Able to deal with ambiguity & & & \\
\hline & Able to deal with complexity & & & \\
\hline & Able to deal with contradictions & & & \\
\hline & Able to deal with uncertainty & & & \\
\hline & Able to deal with incomplete information & NEG & & POS \\
\hline & Objective analysis of technical data & & & \\
\hline & Prioritise information & & & \\
\hline & Sharing information & UNCLR & UNCLR & POS \\
\hline \multirow{7}{*}{$\begin{array}{l}\text { Decision } \\
\text { making }\end{array}$} & Manage risks & & & \\
\hline & Able to deal with new information & & & \\
\hline & Able to deal with variable time pressures & & & \\
\hline & Willing to take decisions & NEG & & POS \\
\hline & \begin{tabular}{|l|} 
Will follow orders and CONOPS \\
\end{tabular} & POS & & NEG \\
\hline & \begin{tabular}{|l|} 
Able to act autonomously \\
\end{tabular} & NEG & & POS \\
\hline & Recognises mistakes/takes action & NEG & & POS \\
\hline \multirow{7}{*}{$\begin{array}{l}\text { Leadership } \\
\text { skills }\end{array}$} & Demands/inspires unquestioning loyalty & POS & & NEG \\
\hline & Encourages constructive criticism/input & & & \\
\hline & Able to motivate others & & & \\
\hline & Able to direct others & & & \\
\hline & Able to accept consequ's of decisions & NEG & & POS \\
\hline & Able to delegate & & & \\
\hline & Able to engender trust & NEG & & POS \\
\hline \multirow{5}{*}{ Innovation } & Willing to take risks & NEG & & POS \\
\hline & Able to manage or balance risk & & & \\
\hline & Able to self-organise, reconfigure & NEG & & POS \\
\hline & Able to think laterally & NEG & & POS \\
\hline & \begin{tabular}{|l|} 
Capable of learning from action/result \\
\end{tabular} & & & \\
\hline \multirow{5}{*}{$\begin{array}{l}\text { Situational } \\
\text { awareness }\end{array}$} & Physical orientation from external cues & & & \\
\hline & Cognitive orientation from external cues & & & \\
\hline & \begin{tabular}{|l} 
Social orientation from external cues \\
\end{tabular} & POS & & NEG \\
\hline & Develop a strategic/tactical overview & & & \\
\hline & Able to assess implications of situation & & & \\
\hline \multirow{5}{*}{ Adaptability } & High robustness & & & \\
\hline & High resilience & & & \\
\hline & High responsiveness & & & \\
\hline & \begin{tabular}{|l|} 
High flexibility \\
\end{tabular} & & & \\
\hline & High adaptability & NEG & & POS \\
\hline \multirow{2}{*}{$\begin{array}{l}\text { Error } \\
\text { managem't }\end{array}$} & Cognitive preparedness & & & \\
\hline & Flexibility in action & NEG & & POS \\
\hline
\end{tabular}

Table 1: Behaviors

As this paper is published in monochrome, the green, amber and red colors in Tables 1,2 and 3 have been replaced with the words POS, UNCLR (unclear) and NEG.

\section{Impact of cultural attribute values on the ability to perform in particular environments}

It is obvious that military environments vary considerably in terms of climate, terrain, etc. The cultural context, within which military operations take place, also varies.

As stated earlier, agents or systems exhibiting certain positions on the cultural attribute pairings will inhibit or facilitate agent or system performance in an environmental 
context exhibiting certain characteristics. For example, if the degree of uncertainty is considered to be 'fuzzy role and task definition', then a system position towards the orthodox end of the orthodox vs. proactive pairing will be detrimental. Table 2 shows the current set of environmental characteristics, with the corresponding scores for one of the cultural attribute pairings.

\begin{tabular}{|c|c|c|c|c|}
\hline $\begin{array}{c}\text { Environ- } \\
\text { ment class }\end{array}$ & Class characteristics & 톨 ? & 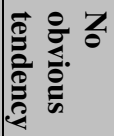 & 氞: \\
\hline \multirow{8}{*}{$\begin{array}{l}\text { Command } \\
\text { structure and } \\
\text { style }\end{array}$} & Centralised Structure & POS & & NEG \\
\hline & Decentralised Structure & NEG & & POS \\
\hline & Authoritative/interventionist & & & \\
\hline & Collaborative/control free & POS & UNCLR & UNCLR \\
\hline & \begin{tabular}{|l} 
Formal communication structure \\
\end{tabular} & & & \\
\hline & Informal communication structure & & & \\
\hline & Strong directive leadership & & & \\
\hline & Consensus based leadership & POS & POS & UNCLR \\
\hline \multirow{6}{*}{$\begin{array}{l}\text { Function/ } \\
\text { authority/ } \\
\text { skills } \\
\text { distribution }\end{array}$} & Stove-piped function distribution & POS & & NEG \\
\hline & Dispersed function distribution & NEG & & POS \\
\hline & Centralised authority over actions & POS & & NEG \\
\hline & Delegated authority over actions & NEG & & POS \\
\hline & \begin{tabular}{|l} 
Specialist skill set available \\
\end{tabular} & & & \\
\hline & Multi-skilling predominates & & & \\
\hline \multirow{4}{*}{$\begin{array}{l}\text { Degree of } \\
\text { inter- } \\
\text { operability }\end{array}$} & Largely heterogeneous systems & NEG & & POS \\
\hline & Largely homogenous systems & & & \\
\hline & Largely heterogeneous SOPs & & & \\
\hline & Largely homogenous SOPs & & & \\
\hline \multirow{6}{*}{$\begin{array}{l}\text { Degree of } \\
\text { uncertainty } \\
\text { and risk }\end{array}$} & Clear role and task definition & & & \\
\hline & Fuzzy role and task definition & & & \\
\hline & Defined rules of engagement & & & \\
\hline & Broader rules of engagement & & & \\
\hline & Small well defined battle space & & & \\
\hline & Large unbounded battle space & NEG & & POS \\
\hline \multirow{4}{*}{$\begin{array}{l}\text { Operation } \\
\text { Tempo }\end{array}$} & Predictable & POS & UNCLR & UNCLR \\
\hline & \begin{tabular}{|l} 
Unpredictable \\
\end{tabular} & UNCLR & UNCLR & POS \\
\hline & Reasonably static & POS & UNCLR & UNCLR \\
\hline & Rapid changes & NEG & UNCLR & POS \\
\hline \multirow{4}{*}{$\begin{array}{l}\text { Decision } \\
\text { making }\end{array}$} & Long horizon & POS & & UNCLR \\
\hline & Short horizon & NEG & & POS \\
\hline & Ad hoc & NEG & & POS \\
\hline & Preconceived & POS & & UNCLR \\
\hline
\end{tabular}

Table 2: Environmental characteristics

As described earlier for the behavior scores, the analysis engine compares the values input for each cultural attribute and evaluates them against each of the environmental characteristics (see Table 2), and applies a similar scoring system. For example, a score on the proactive side of the orthodox/proactive pairing scale would indicate that the system will perform poorly in a highly centralized structure, but will potentially perform well in an environment where the operational tempo is unpredictable.

\section{Presentation of results}

Tables 1 and 2 represent stable sets of data that provide a link between cultural attitude values, and (1) behaviors, (2) environment (or mission) characteristics. These tables, although not yet in their final form, should remain relatively stable, changing only due to new research findings.

It is not possible to show detailed results in this paper due to the large size of the output tables. However, Table 3 provides a visual example of the form of results that one might obtain if the SFMT data gathering tool were completed by a troop commander on behalf of himself, his troop and regiment. The hatched rows in Table 3 represent behaviors that are considered unimportant for the planned mission, role or environment.

\begin{tabular}{|c|c|c|c|c|}
\hline $\begin{array}{l}\text { Skill } \\
\text { class }\end{array}$ & Desired behavior & 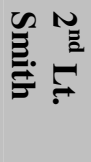 & 룽 & 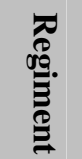 \\
\hline \multirow{6}{*}{$\begin{array}{l}\text { Communi- } \\
\text { cation \& } \\
\text { interaction } \\
\text { skills }\end{array}$} & Say what you mean/mean what you say & POS & POS & UNCLR \\
\hline & W & 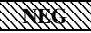 & W & 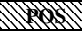 \\
\hline & Dispel conflict & POS & POS & POS \\
\hline & Ability to trust and be trusted & POS & POS & UNCLR \\
\hline & Willingness to collaborate/co-operate & POS & UNCLR & POS \\
\hline & Transparency/openness & POS & POS & UNCLR \\
\hline \multirow{9}{*}{$\begin{array}{l}\text { Information } \\
\text { processing }\end{array}$} & Process information rapidly & POS & POS & UNCLR \\
\hline & Deal with ambiguity & NEG & UNCLR & POS \\
\hline & Deal with complexity & UNCLR & POS & UNCLR \\
\hline & Deal with contradictions & UNCLR & UNCLR & POS \\
\hline & Deal with uncertainty & UNCLR & POS & UNCLR \\
\hline & Deal with incomplete information & UNCLR & UNCLR & POS \\
\hline & Objective analysis of technical data & UNCLR & POS & POS \\
\hline & Prioritize information & UNCLR & POS & POS \\
\hline & Sharing information & POS & POS & NEG \\
\hline \multirow{7}{*}{$\begin{array}{l}\text { Decision } \\
\text { making }\end{array}$} & Manage risks & UNCLR & UNCLR & POS \\
\hline & Deal with new information & UNCLR & POS & UNCLR \\
\hline & Deal with variable time pressures & UNCLR & POS & NEG \\
\hline & Willingness to take decisions & POS & POS & UNCLR \\
\hline & 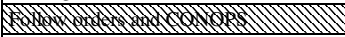 & m & 1 & W \\
\hline & Act autonomously & POS & UNCLR & UNCLR \\
\hline & \begin{tabular}{|l|} 
Recognize mistakes/take action \\
\end{tabular} & UNCLR & POS & POS \\
\hline \multirow{7}{*}{ Leadership } & 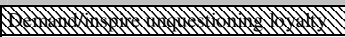 & 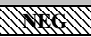 & 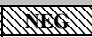 & 11 \\
\hline & Encourage constructive criticism/input & POS & POS & POS \\
\hline & \begin{tabular}{|l} 
Motivate others \\
\end{tabular} & POS & POS & UNCLR \\
\hline & L & Im & W & Mm \\
\hline & Accept consequences of decisions & POS & POS & UNCLR \\
\hline & \begin{tabular}{|l|} 
Delegate authority \\
\end{tabular} & UNCLR & \begin{tabular}{|l|} 
UNCLR \\
\end{tabular} & UNCLR \\
\hline & Engender trust & POS & POS & UNCLR \\
\hline \multirow{5}{*}{ Innovation } & Take risks (as appropriate) & POS & POS & UNCLR \\
\hline & Manage or balance risk & NEG & UNCLR & POS \\
\hline & Can self-organize, reconfigure & POS & POS & UNCLR \\
\hline & - & 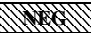 & 1 & 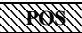 \\
\hline & Learning from action/result & POS & POS & UNCLR \\
\hline \multirow{5}{*}{$\begin{array}{l}\text { Situational } \\
\text { awareness }\end{array}$} & Physical orientation from external cues & POS & POS & UNCLR \\
\hline & A'L & m & MIn & Im \\
\hline & Social orientation from external cues & NEG & NEG & NEG \\
\hline & Develop a strategic/tactical overview & NEG & POS & POS \\
\hline & Assess implications of situation & UNCLR & POS & POS \\
\hline \multirow{5}{*}{ Adaptability } & Robustness & POS & POS & POS \\
\hline & Resilience & POS & POS & POS \\
\hline & Responsiveness & UNCLR & POS & NEG \\
\hline & Flexibility & POS & POS & UNCLR \\
\hline & Adaptability & UNCLR & POS & UNCLR \\
\hline \multirow{2}{*}{ Error mgmt } & Cognitive preparedness & UNCLR & UNCLR & POS \\
\hline & Flexibility in action & POS & POS & UNCLR \\
\hline
\end{tabular}

Table 3: Extract from sample analysis results for behavior

\section{Further work}

Following completion of the current version of the SFMT, it will be evaluated via a wide range of military and other scenarios, prior to the development of a final version and recommendations for additional work. Many issues are still to be resolved, for example: 
- What are the optimum sets of cultural factors and behavioral/skill classes that achieve comprehensiveness without confusing overlaps?

- Are the environmental factors too environment-specific to be transferable across environments?

- Who should input the soft factor values?

\section{Conclusions}

Major changes are taking place in terms of the type of warfare that Western armies are fighting. Whereas ten years ago, the expectation in the West was that the main threats would arise from conventional high intensity warfare, now it is increasingly accepted that the West will primarily face asymmetric, complex irregular warfare.

One result of the above changes is the need for better protection and support for ground troops, including the provision of increasingly sophisticated semi/autonomous vehicles. A further result is the proliferation of multinational forces and non-governmental organizations. These have implications in terms of increasing cultural problems associated with understanding and interfacing with personnel and systems.

The SEAS DTC has supported research work at Loughborough University, UK on cultural factors. This work has resulted in the development of a soft factors modeling tool (SFMT) that enables individuals', groups' and organizations' cultures to be evaluated against behavioral and environmental requirements.

The SFMT is still at the prototype stage and many issues are, as yet, unresolved. Following completion of the current version, it will undergo detailed evaluation.

\section{Acknowledgements}

The work reported in this paper has been supported by the UK Ministry of Defence-funded Systems Engineering for Autonomous Systems (SEAS) Defence Technology Centre.

\section{References}

Dorman,, A.M. 2008. Transforming to Effects-based Operations: Lessons from the United Kingdom Experience. Strategic Studies Institute, US Army War College, Carlisle, PA, USA, January 2008, 63 pages. Can be downloaded from:

www.strategicstudiesinstitute.army.mil/pdffiles/PUB831.p df

Flascovich J. and Hartel C.R. eds. 2008. Human Behavior in Military Contexts. Committee on Opportunities in Basic Research in the Behavioral and Social Sciences for the US Military, National Research Council.

Helmreich, R.L. and Merritt, A.C. 1998. Culture at Work in Aviation and Medicine. Aldershot, UK, Ashgate.
Hoffman, F.G. 2006. Complex, Irregular Warfare: The Next Revolution in Military Affairs. Orbis (Elsevier), 50(3): 395-411.

Hoffman, F.G. 2007. Conflict in the 21st Century: The Rise of Hybrid Wars. Potomac Institute for Policy Studies, Arlington, USA, December 2007, 72 pages. Can be downloaded from:

http://www.potomacinstitute.org/publications/Potomac_Hy bridWar_0108.pdf

Hofstede, G. 1984. Culture's Consequences: International Differences in Work-Related Values. Beverley Hills, Sage.

Hofstede, G. 1991. Cultures and organizations. London, McGraw-Hill.

International Institute for Strategic Studies. 2005. Complex Irregular Warfare: The Face of Contemporary Conflict. In Military Balance, 105(1): 411-420.

Johnson, P., Siemieniuch, C.E. and Woodhead, M.A.. 2007. Description of 1st Prototype Version of Soft Factors Modelling Tool, Technical Report, SEIC-RP-0605, SEIC, Dept. of Electronic \& Electrical Engineering, Loughborough University, Leics., UK.

Krause, M.G. 2007. Square Pegs for Round Holes: Current Approaches to Future Warfare and the Need to Adapt. Land Warfare Studies Centre Working Papers, Australia, June 2007, ISBN 9780642296511, 46 pages.

Norton-Taylor, R. 2007. Titan Rain - how Chinese hackers targeted Whitehall. Guardian (newspaper), UK, $5^{\text {th }}$ September 2007. Can be viewed at:

http://www.guardian.co.uk/technology/2007/sep/04/news.i $\underline{\text { nternet }}$

Qiao, L. and Wang, X. 1999. Unrestricted Warfare. Beijing: PLA Literature and Arts Publishing House.

Qiao, L. and Wang, X. 2002. Unrestricted Warfare: China's Master Plan to Destroy America. Pan American Publishing Company.

Schneider, W. 2007. Asymmetric Military Aspirations and Capabilities of the People's Liberation Army of the People's Republic of China. US-China Economic and Security Commission, Washington DC, March 2007. Can be downloaded from:

http://www.uscc.gov/hearings/2007hearings/transcripts/ma r_29_30/schneider.pdf

Siemieniuch C.E. \& Meese N.C. 2006. Technical Deliverable Report SEIC-RP-520, SER006, SEIC, Dept. of Electronic \& Electrical Engineering, Loughborough University, Leics., UK. 